\title{
CORRECTION
}

View Article Online

View Journal | View Issue

\section{Correction: Roll-to-roll infrared (IR) drying and sintering of an inkjet-printed silver nanoparticle ink within 1 second}

3, 11974

\author{
Enrico Sowade, ${ }^{a}$ Hyunkyoo Kang, ${ }^{\star a}$ Kalyan Y. Mitra, ${ }^{a}$ Oliver J. Weiß, \\ Jürgen Weber ${ }^{\mathrm{b}}$ and Reinhard R. Baumann ${ }^{\mathrm{ac}}$
}

DOI: $10.1039 / c 5 t c 90180 d$

www.rsc.org/MaterialsC

Correction for 'Roll-to-roll infrared (IR) drying and sintering of an inkjet-printed silver nanoparticle ink within 1 second' by Enrico Sowade et al., J. Mater. Chem. C, 2015, DOI: 10.1039/c5tc02291f.

The reference citations that appear in Fig. 1 are incorrect. The updated version of this figure with correct reference citations is provided below.

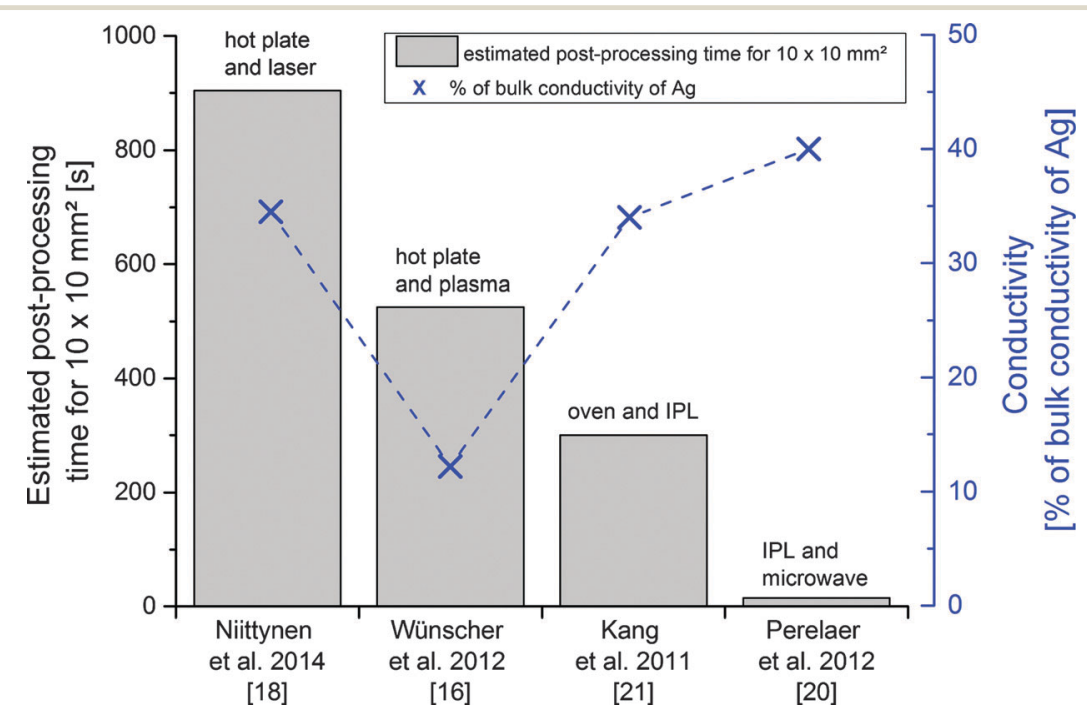

Fig. 1 A comparison of estimated post-processing time and the percentage of bulk Ag conductivity for printed Ag nanoparticle layers using different combinations of drying and sintering methods based on literature sources.

The Royal Society of Chemistry apologises for these errors and any consequent inconvenience to authors and readers.

\footnotetext{
${ }^{a}$ Digital Printing and Imaging Technology, Institute for Printing and Media Technology, Reichenhainer Str. 70, 09126 Chemnitz, Germany. E-mail: hyunkyoo@gmail.com

${ }^{b}$ Development Infrared Process Technology, Heraeus Noblelight, Reinhard-Heraeus-Ring 7, 63801 Kleinostheim, Germany

${ }^{c}$ Department Printed Functionalities, Fraunhofer Research Institute for Electronic Nano Systems (ENAS), Technologie-Campus 3, 09126 Chemnitz, Germany
} 